\title{
THE CAUSAL EFFECT OF AIR POLLUTION ON INTERNATIONAL TOURIST ARRIVALS
}

\section{Arief Rahman}

Universitas Indonesia

Email: arief.rahman@outlook.com.au

\begin{abstract}
This paper adopts two approaches in examining the effects of air pollution on foreign tourist visits, namely instrumental variables and long-run growth, using dataset of 141 countries in period 2010-2017. The log of value added of industry per capita is used as an instrumental variable for the log of mean annual exposure of PM2.5 air pollution. Long-run growth of international tourist arrivals and mean annual exposure of PM2.5 air pollution are used in analyzing the long-run growth effect. The findings are that the level of air pollution has a negative influence on the number of foreign tourists visiting a country. Another finding is that the tourist arrival-air pollution elasticity has negative value and less than one.
\end{abstract}

Keywords: Tourist, Air Pollution, IV, Long-Run Growth

\section{Introduction}

The current condition of the world in which the growing understanding of globalization makes it easier for the people of a country to travel to other countries. Many motivations that move them to travel abroad, one of which is in order to travel. UNWTO (2018), a world organization engaged in tourism, explained that currently the contribution of the tourism sector to the level of world GDP is around 10 percent and provides 10 percent of the types of jobs in the world.

Globalization also means that the capital owned by a country can cross overseas easily so that many factories are established in order to approach production factors. This can affect the level of air pollution around the location of the plant. Air pollution and foreign tourist visits are not suitable partners. Air pollution is alleged to have a negative influence on foreign tourist visits due to the disturbances caused, such as health problems, respiratory or visual disturbances, all of which result in discomfort for tourists.

However, tourist visits to an area both local and foreign are also allegedly increasing the level of air pollution in the area, especially in areas that have tourist attractions (Saenz-de-Miera \& Rosselló, 2014). This has implications that there may be a reciprocal relationship between air pollution and visits by international tourists.

This essay adopts an instrumental variable strategy in order to identify the effects of air pollution with international tourist visits. The instrument used is the value added industry per capita in determining the magnitude of its influence on international 
tourist visits through air pollution. In addition, this essay also explores the long-term effects of air pollution and visits by foreign tourists. Both also control several factors in finding these links.

The findings in this essay are expected to provide an economic value for efforts to reduce air pollution so that it becomes one of the guidelines for policy makers in a country in determining air pollution reduction strategies in their region.

\section{PM2.5 Air Pollution and International Tourist Arrivals}

Research on the relationship between air pollution and international tourist arrivals has been carried out. Most used sample data within a country. One of them is research conducted by (Deng, $\mathrm{Li}, \& \mathrm{Ma}, 2017$ ) He examined the effect of air pollution on the arrival of international tourists to China using the spatial econometrics method. The findings confirm that air pollution has a significant direct negative effect on international tourists visiting China. There is evidence that air pollution in neighboring provinces has a significant negative impact on international tourist arrivals in the local province. When air pollution in neighboring provinces becomes serious, international tourists may not travel to the local province

Other research on the effects of air pollution on international tourist arrivals has been carried out by (Gani \& Clemes, 2017) Just like the research mentioned above, they do it within the scope of one country namely New Zealand. They examined the factors that were taken into consideration for foreigners to visit New Zealand as tourists. One important factor included in his research was the level of air pollution in New Zealand, but the results obtained were not significant.

The influence of air pollution on international tourist arrivals is hypothesized to have a negative influence. This is because tourists when they come to a place expect a pleasant experience and air pollution does not provide such a pleasant experience. The World Health Organization (Organization, 2019) have released that around 4.2 million deaths in the world are related to air pollution, mainly due to heart disease, stroke, chronic obstructive pulmonary disease, lung cancer, and acute respiratory infections in children and pollutants that prove to be the greatest the effect is particulate matter (PM). $\mathrm{PM}$ is able to enter deep into the respiratory tract and blood vessels causing cardiovascular, cerebrovascular and respiratory impacts.

For many countries GDP percapita has a high correlation with wealth (Lange et al. 2018). The wealth of a country includes all of its capital, one of which is in the form of infrastructure owned. As explained earlier, tourists looking for pleasant experiences and facilities and infrastructure owned by a country can influence that experience. So that for tourists, the better the quality and quantity of facilities and infrastructure, especially those related to tourism, the higher the hope of getting such a pleasant experience. Then GDP per capita can have a positive relationship with international tourist arrivals.

The achievement of a country in good governance is a positive factor that attracts tourists to come to the country (Gani \& Clemes, 2017). Another factor that might be a determining factor for someone visiting a country is the level of security in 
the country. The higher the level of security at a tourist destination, the more comfortable it is for tourists to spend their free time there. Imagine when tourists are having fun suddenly at that location there is a riot, for example, the location could be left by tourists.

UNESCO through the world heritage convention has made a list that contains the world heritage site in the form of natural sites and cultural sites throughout the world. To be included in the list, the site must meet at least one predetermined criterion (UNESCO, 2019). This site can be a tourist destination that provides potential for the experience sought by potential tourists. So that more and more a country has a world heritage site might be able to use it to attract tourists coming to the country.

Every country has an industrial sector in supporting its economy. The industrial sector also has a negative influence especially on the environment. The results of waste that is not managed properly will pollute the air, soil and water in the area. With this influence, activities carried out in the industrial sector can increase the level of air pollution.

\section{Research Method \\ Empirical Approach}

Estimation Model

The model for estimation is:

$$
\begin{aligned}
& \text { loginttoua }_{i, t}=\beta_{0}+\beta_{1} \operatorname{logpm}_{2.5_{i, t}}+\beta_{2} \operatorname{loggdpc}_{i, t}+ \\
& \beta_{3} \text { wgindex }_{i, t}+\beta_{4} \text { gpindex }_{i, t}+\beta_{5} \text { unescowh } \\
& i, t
\end{aligned}
$$

where the dependent variable is log number of arrivals international tourism annually for the period 2010-2017 and 141 countries. The independent variable is log mean annual exposure PM2.5 air pollution in each country for sample period. There are four control variables used in this model. First, it is log GDP per capita. World governance index and global peace index are also used as the third and fourth of the control variables. Last control variable is the amount of UNESCO world heritage sites owned by a country.

Equation 1 is initially estimated using a liner panel model (LPM) with fixed effect. It is assumed that the country-specific effects are correlated with the independent variables (Lange, Wodon, \& Carey, 2018). Estimated standard errors are robust to heteroscedasticity and are clustered at the country level to account for possible serial correlation (Burke, 2012).

Instrumenting for PM2.5 Air Pollution

It is possible that annual exposure PM2.5 air pollution is endogenous to the system. An increase in tourist numbers could increase air pollution in the area (Saenzde-Miera \& Rosselló, 2014). International tourist arrivals may be harmful for environment, as they may accelerate the producing of PM2.5 air pollution in destination country. It may come from industries that producing tourism related goods and services. 
It may also from transportation vehicle for the mobility of tourists. Given the infeasibility of controlling unobservable factors, IV approach is needed to obtain consistent estimates of the impact of PM2.5 air pollution on international tourist arrivals, and to ensure that estimates represent the cause and effect, not just correlation.

The IV strategy is to instrument for log of PM2.5 air pollution using log of value added industry per capita. It is obtained by dividing value added industry by population per country in sample period. The instrument is not without limitation. Value added industry per capita may not always be exogenous, as it might in some instances be affected by policies taken by a country related to its industry sector. The exclusion restriction is that the instrument is orthogonal to the error term in equation 1 (Burke, 2012), so that it is only correlated with international tourist arrivals via its impact on PM2.5 air pollution. There are some ways in which the exclusion restriction may be broken such as manufacture of tourism related goods and services in the transport sector, food and beverages, and hotel equipment (Deloitte, 2008) that encourage international tourists to visit. Furthermore, there may also be negative effect in which tourists see that industry is repulsive in appearance so that it would not attract them to come.

\section{Exploring Long-Run Effect Model}

The model for long-run estimation is adopted from Stern et al. (2017):

$$
\begin{aligned}
& \hat{I}_{i}=\alpha_{0}+\alpha_{1} \widehat{P}_{i}+\beta_{1} P_{i 0}+\beta_{2} I_{i 0}+\beta_{3} \text { lgdppc }_{i}+\beta_{4} \text { wgindex }_{i}+\beta_{5} \text { gpindex }_{i}+ \\
& \beta_{\mathrm{f}} \text { unescowh } \text { hin }_{i}+\varepsilon_{\bar{i}}
\end{aligned}
$$

where hats indicate long-run growth rates, that is, $\hat{I}_{i}=\left(I_{i T}-I_{i 0}\right) / T$ and $\widehat{P}_{i}=\left(P_{i T}-P_{i 0}\right) / T$, where $T$ is the final year of the time series in levels, 0 indicates the initial year, and $i$ indexes countries (Stern et al 2017). $I$ is the log of international tourist arrivals, and $P$ is the $\log$ of PM2.5 air pollution. The sample mean is deducted from each of the control variables. $\alpha_{1}$ is an estimate of the tourist-air pollution elasticity, which is expected to be negative, and $\alpha_{0}$ is an estimate of the mean of $\widehat{E}_{i}$ for countries with zero PM2.5 air pollution growth and the control variables at their sample means and equals to the average time effect. If $\alpha_{0}<0$ then in the absence of PM2.5 air pollution growth (and when the other viables are at their mean or default values), there is on average a reduction in international tourist arrivals over time, and vice versa (Stern, Gerlagh, \& Burke, 2017).

$P_{0}$ and $I_{0}$ are the initial levels of PM2.5 air pollution and international tourist arrivals, included to test convergence-type theories. If $\beta_{2}<0$, then there is beta convergence in international tourist arrivals (Stern et al. 2017). If $\beta_{1}=-\beta_{2}$ then there is beta convergence in international tourist arrivals without an additional effect of the initial level of PM2.5 air pollution (Stern et al., 2017). 


\section{Results and Discussion}

The number of arrivals of international tourism data are sourced from the (Organization, 2019). The mean annual exposure of PM2.5 air pollution data are also obtained from the (Organization, 2019). The GDP per capita PPP (constant 2011 international \$) data are acquired from the (Organization, 2019). The world governance index is constructed from the Worldwide Governance Indicators (WGI) project (Kaufmann \& Kraay, 2019) by calculating the average of four dimensions of governance: voice and accountability, political stability and absence of violence, rule of law, and control of corruption (Gani \& Clemes, 2017). This dataset summarizing the views on the quality of the traditions and institutions by which authority in a country (Kaufmann \& Kraay 2019). The Global Peace Index (GPI) data are produced by the Institute for Economics and Peace (IEP) (2019) as a measure of global peacefulness. The world heritage list is a list of cultural sites and natural sites which are of outstanding universal value and meet at least one of selection criteria created by UNESCO World Heritage Convention (UNESCO, 2019). The value added of industry (constant 2010 US\$) dataset is the dataset of net output of industry including mining, manufacturing, construction, electricity, water, and gas and is generated from the World Bank (2019). The last dataset used in this research is total population data per country collected also from the (Organization, 2019). For the purpose of exploring long-run growth effects of PM2.5 air pollution on international tourist arrivals, all datasets are calculated on average per country.

The estimation sample consists of 1,055 observations for 8 years (2010-2017) and 141 countries. Belarus is excluded from the sample given that it has a large gap on international tourist arrivals between 2010 and 2017. Summary statistics are presented in Table $1 \mathrm{a}$ and $1 \mathrm{~b}$.

Table 1a Summary statistics of panel data

\begin{tabular}{|c|c|c|}
\hline & Mean & $\begin{array}{l}\text { (Standard } \\
\text { deviation) }\end{array}$ \\
\hline International tourism, number of arrivals $\mathrm{t}_{\mathrm{t}}$ & $7,656,399$ & $(13,718,384)$ \\
\hline PM2.5 air pollution, mean annual exposure $\left(\mu \mathrm{g} / \mathrm{m}^{3}\right)$ & 28.551 & $(18.679)$ \\
\hline GDP per capitat, PPP (constant 2011 international \$) & $18,210.240$ & $(18,751.470)$ \\
\hline Worldwide Governance Indicatorst & -0.057 & $(0.884)$ \\
\hline Global Peace Index & 1.993 & $(0.436)$ \\
\hline UNESCO world heritage owned ${ }_{t}$ & 6.653 & $(9.012)$ \\
\hline \multirow[t]{2}{*}{$\begin{array}{l}\text { Industry per capitat (including construction), value } \\
\text { added (constant } 2010 \text { US\$) }\end{array}$} & $4,081.217$ & $(7,126.049)$ \\
\hline & Sum & \\
\hline Countries & 141 & \\
\hline Observations & 1,055 & \\
\hline
\end{tabular}


Table 1b Summary statistics of long-run growth

\begin{tabular}{|c|c|c|c|c|c|c|}
\hline $\mathrm{N}$ & Mean & St. Dev. & Min & $\operatorname{Pctl}(25)$ & $\operatorname{Pctl}(75)$ & Max \\
\hline \multicolumn{7}{|c|}{ International tourist arrival mean annual growth rate $2010-2017$ : } \\
\hline 141 & 0.057 & 0.072 & -0.221 & 0.032 & 0.090 & 0.261 \\
\hline \multicolumn{7}{|c|}{ PM2.5 air pollution mean annual growth rate 2010-2017: } \\
\hline 141 & -0.015 & 0.025 & -0.147 & -0.031 & -0.001 & 0.053 \\
\hline
\end{tabular}

A negative association between PM2.5 air pollution and international tourist arrivals is evident in Figure 1, which plot the average mean annual exposure of PM2.5 air pollution for countries in the estimation sample for 8 years (2010-2017). A reduction in mean annual exposure PM2.5 air pollution is followed by an increase in number of arrivals international tourism.

\section{Figure 1 The Relationship Between International Tourist Arrivals and PM2.5 Air Pollution}

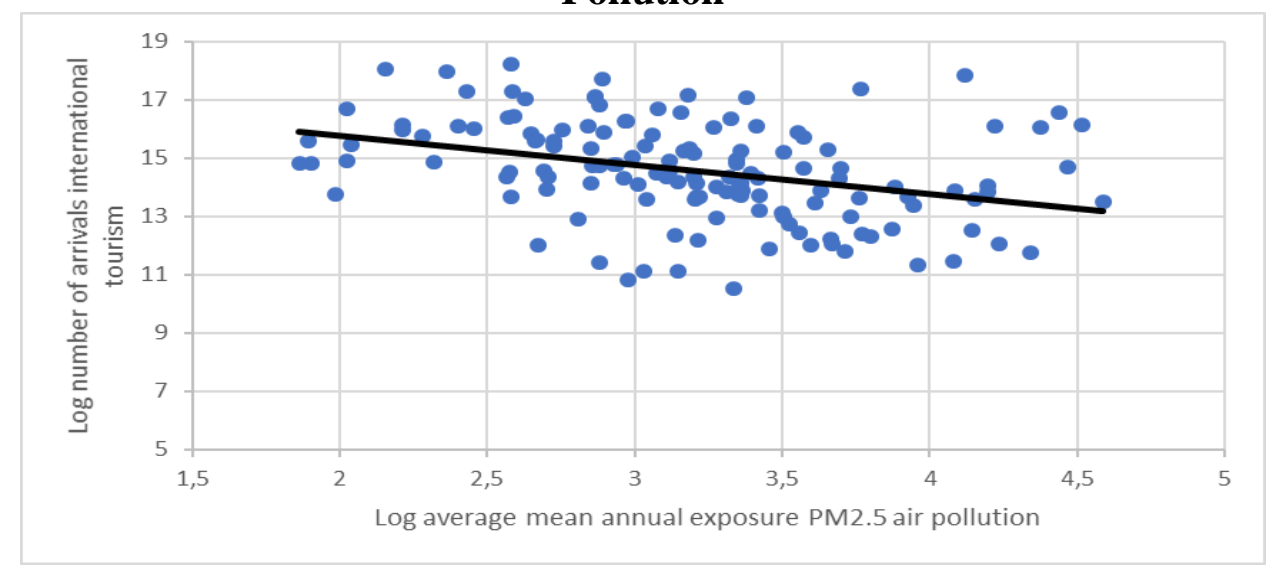

Source: (Organization, 2019)

Table $1 \mathrm{~b}$ shows the summary statistics of international tourist arrivals and PM2.5 air pollution long-run growth. International tourist arrivals are rising on average across countries by more than 5 percent per annum while PM2.5 air pollutions level is falling at 1.5 percent per annum. Variations in the rate of change across countries are much larger for international tourist arrivals than for PM2.5 air pollution, as the standard deviation of the international tourist arrivals growth rate is approximately three times as large as that for PM2.5 air pollution. Based on these simple statistics, the naïve estimates of the tourists-air pollution elasticity would be -0.263 for the data set. As we will see, separating the total effect into time and growth effects greatly modifies the latter estimate.

Figure 2 shows a negative correlation between the long-run average growth rate of PM2.5 air pollution and the long-run average growth rate of international tourist arrivals. Growing PM2.5 air pollution typically see decreases in international tourist 
arrivals while shrinking PM2.5 air pollution tends to have increasing international tourist arrivals.

Figure 2 Growth Rates of PM2.5 Air Pollution and International Tourist Arrivals

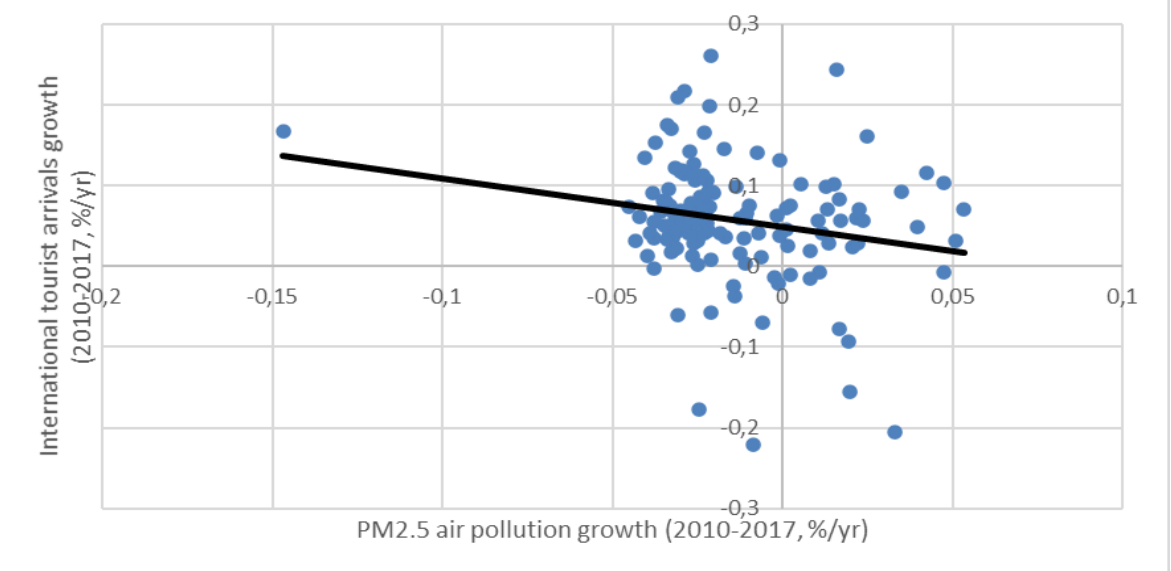

Source: (Organization, 2019)

Figure 3 shows beta convergence for international tourist arrivals for the sample of countries. Countries with high initial number of arrivals international tourism tend to have lower international tourist arrivals growth rate.

Figure 3 Convergence In International Tourist Arrivals

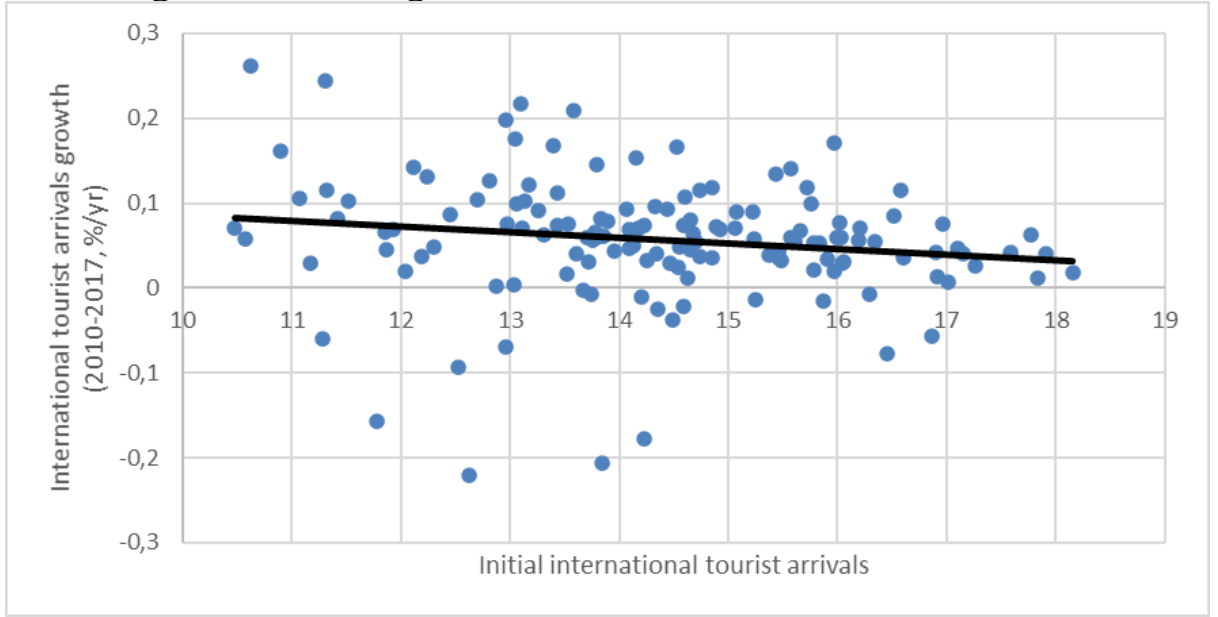

Source: (Organization, 2019)

\section{Linear Panel Model Results}

The LPM results are presented in Table 2 and explain about 35 percent of the variation in the data. The results show that the average annual log exposure to PM2.5 air pollution has a negative impact on the log international tourist arrivals. Estimates of the impact of air pollution on international tourist arrivals are statistically significant at the 1 percent level in linear panel models with fixed effects. Estimates show that a one percent increase in annual exposure to PM2.5 air pollution reduces on average more than half a percent of international tourism arrivals. This result shows that a country with high level of air pollution would become less desirable country for international 
tourists to visit because they put their health and comfortable on top priority and air pollution would decrease those.

The results in the control variable indicate that the level of income of a country has a high influence on the arrival of international tourists. The log estimated GDP per capita coefficient is statistically significant and shows that an increase in GDP per capita of 1 percent increases international tourist arrivals by about 1.2 percent of the average overtime per country. Differences in institutions also have a statistically significant estimated coefficient. An increase in the World Governance Index of a country with one increases international tourist arrivals by more than 25 percent overtime. Surprisingly, tourists in their decision-making process do not consider much the level of state security. This is indicated by the estimated coefficient of the World Governance Index which is not statistically significant. The estimated coefficient of UNESCO world heritage sites owned by a country is also not statistically significant. This tells us that tourists do not place high consideration on deciding their destination.

Table 2 Linear panel model estimation results Dependent variable: Log international tourist arrivals in year $t$

\begin{tabular}{lc}
\hline & Coefficients \\
\hline Log PM2.5 air pollution $_{\mathrm{t}}$ & $-0.564^{* * *}$ \\
& $(0.132)$ \\
Log GDP per capita & $1.199^{* * *}$ \\
& $(0.232)$ \\
World governance index & $0.251^{*}$ \\
& $(0.130)$ \\
Global peace index & -0.079 \\
& $(0.127)$ \\
UNESCO world heritage & 0.023 \\
& $(0.018)$ \\
\hline $\mathrm{R}^{2}$ & 0.344 \\
Observations & 1,055 \\
Countries & 141 \\
Years: $2010-2017$ & \\
\hline
\end{tabular}

Note: The linear panel model used fixed effects. Robust standard errors grouped by country are in parentheses. The world governance index is measured by an annual estimate of the four broad dimensions of governance (i.e. voice and accountability, political stability and absence of violence / terrorism, rule of law, and control of corruption). * Significant at $10 \%$. *** Significant at $1 \%$.

Instrumental Variables Model Results

LPM results can suffer bias due to the endogenicity of annual exposure to PM2.5 air pollution. Before presenting IV results, it is important to examine the direct impact of the instrument on international tourist arrivals. This can be seen in Table 3, which presents reduced-form estimation controls for time-varying control sets and explain 
more than 30 percent of the variation in the data.. Estimates do not provide statistically significant evidence about the effect of per capita value-added industry on international tourist arrivals.

\section{Table 3 Reduced-form results}

Dependent variable: Log international tourist arrivals in year $t$

\begin{tabular}{lc}
\hline & Coefficients \\
\hline Log value added industry per capita & -0.010 \\
& $(0.187)$ \\
\hline $\mathrm{R}^{2}$ & 0.309 \\
Observations & 1,055 \\
Countries & 141 \\
Years: $2010-2017$ & \\
\hline
\end{tabular}

Note: The linear panel model used fixed effects. Robust standard errors grouped by country are in parentheses. Estimates include the full set of controls used in the estimates in Table 2 (coefficient estimates not shown).

IV estimates of equation 1 are shown in Table 4. Partial R-squared and F statistics on the excluded instruments are presented. The F statistic on the excluded instruments is the Stock-Yogo weak instruments test statistic. 5 percent significance level critical values for Stock-Yogo tests of both 30 percent and 5 percent maximal Fuller relative bias are also shown.

The instrument explains nearly 22 percent of the variation in mean annual exposure PM2.5 air pollution, however it does not pass the Stock-Yogo weak instrument test. The coefficient on the instrument in the first-stage regressions is statistically significant and of the expected signs: increases in value added industry per capita results in higher mean annual exposure PM2.5 air pollution.

The IV results on mean annual exposure PM2.5 air pollution suggests a negative effect of mean annual exposure PM2.5 air pollution on international tourist arrivals, but one which is not statistically significant. The result on the control variables are similar to those in the LPM specification. 
Table 4 IV regression results

Dependent variable: Log international tourist arrivals in year $t$

\begin{tabular}{lcc}
\hline Estimations & LPM & IV \\
\hline Instrument & None & $\begin{array}{c}\text { Log value added industry per } \\
\text { capita }\end{array}$ \\
\hline Log PM2.5 air pollution $\mathrm{t}_{\mathrm{t}}$ & - & -0.058 \\
& $0.564^{* * *}$ & $(1.125)$ \\
Log GDP per capita $\mathrm{t}$ & $(0.132)$ & $1.431^{* * *}$ \\
& $1.199^{* * *}$ & $(0.435)$ \\
World governance index $\mathrm{t}$ & $(0.232)$ & $0.241^{*}$ \\
& $0.251^{*}$ & $(0.142)$ \\
Global peace index & $(0.130)$ & -0.101 \\
& -0.079 & $(0.123)$ \\
UNESCO world heritage & 0.030 \\
& $(0.127)$ & $(0.027)$ \\
\hline First-stage coefficients & 0.023 & \\
$\quad$ Log value added industry per & $(0.018)$ & $0.165^{* *}$ \\
capita & & \\
$F$ statistic on excluded instruments & & 4.848 \\
Stock-Yogo critical value & & $12.71 / 24.09$ \\
Partial $R^{2}$ on excluded instruments & & 0.219 \\
Observations & & 1,055 \\
Countries & & 141 \\
Years: $2010-2017$ & & \\
\hline
\end{tabular}

Note: The linear panel model is used with fixed effects. Robust standard errors grouped by country are in parentheses. The critical value of the Stock-Yogo is the critical value of the 5\% significance level for weak instrument tests based on, respectively, 30\% and 5\% maximum Fuller relative bias. The null of weak instruments are rejected if the F statistic on the excluded instruments exceeds the Stock-Yogo critical value. The results in column LPM are identical to those in Table 2. *** Significant at $1 \%$.

Long-Run Growth Model Results

Table 5 presents the result for equation (1). The model in table 5 explains about 13.5 percent of the variation in the data. The time effect is positive and significant (more than 27 percent per annum). The arrivals-air pollutions elasticity is -0.794 and significantly different from -1 . The coefficient of log initial PM2.5 air pollution is not statistically significant, on the other hand the coefficient of log initial international tourist arrivals is statistically significant. Noticeably, the annual rate of conditional convergence for international tourist arrivals at a rate about 2 percent per year is similar to the 'iron law of convergence' (Barro, 2015). 
Table 5 Long-run growth model estimation results

Dependent variable: Long-run growth rate of international tourist arrivals

\begin{tabular}{lc}
\hline Constant & Coefficients \\
$\widehat{P}_{i}$ & $0.272^{* *}$ \\
& $(0.121)$ \\
$P_{i 0}$ & $-0.794^{* * *}$ \\
& $(0.269)$ \\
$I_{i 0}$ & 0.006 \\
& $(0.019)$ \\
Log GDP per capita & $-0.018^{* * *}$ \\
& $(0.006)$ \\
World governance index & -0.0001 \\
& $(0.009)$ \\
Global peace index & 0.014 \\
& $(0.017)$ \\
UNESCO world heritage & -0.00004 \\
& $(0.001)$ \\
R & $0.001 *$ \\
Breusch-Pagan test & $(0.121)$ \\
Observations & 0.135 \\
Years: 2010-2017 & 15.235 \\
\hline
\end{tabular}

Note: Figures in parentheses are standard errors for the regression coefficients and $p$ values for Breusch-Pagan test statistics. Figures in square brackets are the $t$-statistic for the difference between the coefficient and unity. The world governance index is measured by an annual estimate of the four broad dimensions of governance (that is voice and accountability, political stability and absence of violence/terrorism, rule of law, and control of corruption). The sample mean is subtracted from all levels variables so that the intercept is an estimate of the mean of $\hat{l}_{i}$ for countries with zero PM2.5 air pollution growth and the continuous levels variables at thee sample mean.* Significant at 10 percent. $* *$ Significant at 5 percent. *** Significant at 1 percent.

The coefficients of control variables are not statistically significant except for UNESCO world heritage sites owned by a country. An increase of UNESCO world heritage sites by one unit increases the long-run growth rate of international tourist arrivals by 0.1 percent on average annually. It tells us that in the long run, the recognition of world organization on endowment's countries in the form of tourist destinations would become significant effect of tourist attractions.

\section{Conclusions}

The findings in this essay suggest that the level of air pollution in a country has a significant negative effect on the number of foreign tourists visiting the country. Another finding is that the use of value added industry per capita to explain air pollution 
shows a positive influence on it. But when applying it as an instrument to explain its influence on the number of foreign tourist visits through the estimated level of air pollution it produces a coefficient that is not significant. This is probably due to a violation of the exclusion restriction assumption in which the instruments used directly influence the dependent variable. For example, the industry will create a negative outlook for potential tourists because of the possibility of air pollution generated as industrial waste. Even so, the industry can also have a direct influence through the industries of goods and services related to tourism.

Exploration of the long-term effects of air pollution on visits of international tourists is the presence of arrivals-air pollution air elasticity of negative value and less than unity significantly. Another finding is that countries with a high number of foreign tourist visits at the beginning of the period tend to have smaller long-term growth rates compared to countries with lower numbers of tourist visits. There is a process of reduction or elimination in the long term gap between countries in terms of the number of visits of foreign tourists.

The findings in this essay show the economic value of reducing air pollution. If so far the reduction of air pollution has only been considered as a cost center at the state budget post, looking at its influence on the number of foreign tourist visits can be seen as an investment to attract tourists, similar to the development of facilities and infrastructure related to tourism. 


\section{REFERENCES}

Barro, R. J. (2015). Convergence and modernisation. The Economic Journal, 125(585), 911-942.

Burke, P. J. (2012). Economic growth and political survival. The BE Journal of Macroeconomics, 12(1).

Deloitte, M. C. S. (2008). The Economic Case for the Visitor Economy. Final Report for Visit Britain), London, Deloitte MCS.

Deng, T., Li, X., \& Ma, M. (2017). Evaluating impact of air pollution on China's inbound tourism industry: A spatial econometric approach. Asia Pacific Journal of Tourism Research, 22(7), 771-780.

Gani, A., \& Clemes, M. D. (2017). The main determinants effecting international visitor arrivals in New Zealand: Some empirical evidence. Tourism Economics, 23(5), 921-940.

Kaufmann, D., \& Kraay, A. (2019). Growth without governance: Policy research working paper 2928. The World Bank Institute and Development Research Group, Viewed, 9.

Lange, G.-M., Wodon, Q., \& Carey, K. (2018). The changing wealth of nations 2018: Building a sustainable future. The World Bank.

Organization, W. H. (2019). Global status report on alcohol and health 2018. World Health Organization.

Saenz-de-Miera, O., \& Rosselló, J. (2014). Modeling tourism impacts on air pollution: The case study of PM10 in Mallorca. Tourism Management, 40, 273-281.

Stern, D. I., Gerlagh, R., \& Burke, P. J. (2017). Modeling the emissions-income relationship using long-run growth rates. Environment and Development Economics, 22(6), 699-724.

UNESCO, I. C. H. (2019). Performing arts (such as traditional music, dance and theatre). 